\title{
Evaluation of the Whole Body Scanner in the Management of Severe Traumas at Armentieres Hospital Centre (France): Scanographic and Clinical Correlation about 180 Cases
}

\author{
Sessi Miralda Kiki1,2*, Hermione Patricia Yekpe Ahouansou², Djivèdé Akanni², \\ Chakib Aiouaz' ${ }^{1}$ Olivier Biaou ${ }^{2}$, Rabiou Cisse ${ }^{3}$ \\ ${ }^{1}$ Radiology Department of Armentieres Hospital Centre, Armentieres, France \\ ${ }^{2}$ Radiology Department of the National Hospital University Centre Hubert Koutoukou MAGA, Cotonou, Benin \\ ${ }^{3}$ Radiology Department of the Hospital University Centre Yalgado OUEDRAOGO, Ouagadougou, Burkina-Faso \\ Email: "gracekik@yahoo.fr
}

Received 13 June 2016; accepted 19 August 2016; published 22 August 2016

Copyright (C) 2016 by authors and Scientific Research Publishing Inc.

This work is licensed under the Creative Commons Attribution International License (CC BY).

http://creativecommons.org/licenses/by/4.0/

(c) (i) Open Access

\section{Abstract}

Goal: This study aims to evaluate the contribution of the whole body scanner in the management of severe traumas. Patient and Method: It is a retrospective analytical study, carried out at the Armentieres Hospital Centre (France) over a period of 14 months. It analyzes computed tomography reports and emergency department results of severe trauma patients immediately stabled at the entrance or stabilized after benefiting from a full body scanner according to Vittel criteria. Results: One hundred eighty patients were included in the study with an average age of 32.71 years old. One hundred and twelve patients $(62.2 \%)$ had at least one clinical sign and only 48 patients presented a lesion on the computed tomography (26.7\%). Sixty-two patients (34.4\%) showed neither clinical signs nor damage in scan. The radio-clinical correlation was bad at spinal and abdominal level, mediocre at brain and chest level, but it was medium in the pelvis. The average radiation dose per patient was $3319.21 \mathrm{mGy} \cdot \mathrm{cm}$. Conclusion: The whole body computed tomography or scanning allows fast images acquisition compatible with emergency situation and with a satisfactory diagnostic reliability, but still remains an irradiating exam. The results of this study lead to reflect on the use of Vittel criteria that could be improved to reduce the number of normal tests carried out.

\footnotetext{
"Corresponding author.
}

How to cite this paper: Kiki, S.M., Yekpe Ahouansou, H.P., Akanni, D., Aiouaz, C., Biaou, O. and Cisse, R. (2016) Evaluation of the Whole Body Scanner in the Management of Severe Traumas at Armentieres Hospital Centre (France): Scanographic and Clinical Correlation about 180 Cases. Open Journal of Radiology, 6, 220-228.

http://dx.doi.org/10.4236/ojrad.2016.63029 


\section{Keywords}

\section{Severe Trauma, Whole Body Computed Tomography or Scanner, Vittel Criteria, Radio-Clinical Correlation}

\section{Introduction}

A severe trauma patient is a patient with a violent trauma, whatever visible lesions [1]. Severe traumas are a public health problem. They are the main causes of death of patients under 40 years old in France [2]. The management of severe trauma is multidisciplinary, based upon an optimal assessment of the lesions.

Medical imaging, especially the whole body computed tomography plays an important role in assessing severe trauma lesion immediately stable or stabilized by appropriate resuscitation [3]. The pre-hospital clinical evaluation of trauma patients is well codified and based on Vittel criteria that define a severe trauma patient. These criteria, supposing to lead to the whole body scan are often used differently, leading to several behaviors [1] [4] [5].

In presence of the large number of tests carried out with or without clinical signs and the expensive nature of the whole body scanner, we then conducted this study so as to appreciate the contribution of test in the management of severe trauma.

\section{Patients and Methods}

Our retrospective and analytical study lasted 14 months (from July 2013 to August 2014). It took place in the radiology department of Armentieres hospital centre in France. It involved the analysis of computed tomography reports and emergency department results of severe trauma patients immediately stable at the entrance or stabilized after receiving a whole body scan.

Were included, severe trauma patients with stable entering or stabilized who received a full body scanner. Were excluded from the study, severe trauma patients with stable entering or stabilized who received a full body scanner, but the emergency records were not usable because insufficiently informed.

Firstly, we have established a list of severe trauma patients from computerized records (PACS: Picture Archiving and Communication System) of the hospital's radiology department with as search criteria "Body scanner". Secondly we have recovered the summary sheets of the transfer to the emergency of these patients, that we have exploited. The presence of at least one of the criteria of Vittel (Table 1) was sufficient to consider the patient as a severe trauma justifying the achievement of a full body scanner.

Clinical examination was considered as negative in the absence of clinical signs or other symptoms related to traumatism. It was considered positive in the presence of a symptomatology or clinical signs related to traumatism.

The tests were performed using helical scanner of 64 slide brand General Electric CT 660 OPTIMA.

\section{Table 1. List of criteria Vittel [3].}

\begin{tabular}{|c|c|}
\hline Evaluation & Criteria of severity \\
\hline Physiological variables & Glasgow score $<13$; Systolic blood pressure $<90 \mathrm{~mm} \cdot \mathrm{Hg}$; Oxygen saturation $<90 \%$. \\
\hline Elements of kinetic & $\begin{array}{l}\text { Ejecting a car; Another passenger died in the same accident; Falling more than } 6 \text { meters; Victim was thrown } \\
\text { or crushed; Overall assessment (vehicle deformation, estimated speed, helmet absence, no belt). }\end{array}$ \\
\hline Anatomical lesions & $\begin{array}{l}\text { Penetrating trauma (head, neck, thorax, abdomen, pelvis, arm, thigh); Flail chest; Severe burns; smoke inhala- } \\
\text { tion; Comminuted fracture of the pelvis; Suspected spinal damage; Amputation at the wrist; ankle or above; } \\
\text { Acute limb ischaemia. }\end{array}$ \\
\hline Prehospital resuscitation & Assisted ventilator; Vascular filling more colloid 1000 mL; Catecholamines. \\
\hline Patient field traumatized & $\begin{array}{c}\text { Patient over } 65 \text { years; Cardiac or coronary insufficiency; Respiratory failure, Pregnancy (second and third } \\
\text { trimester); Disorder of blood dyscrasias. }\end{array}$ \\
\hline \multicolumn{2}{|c|}{$\begin{array}{l}\text { The presence of a single criterion is sufficient to characterize the severity of the injury, except for the land where it is a case by case } \\
\text { evaluation. Furthermore, the criteria of extreme gravity were defined because associated with very high mortality: systolic blood } \\
\text { pressure below } 65 \mathrm{~mm} \cdot \mathrm{Hg} \text { (mortality: } 65 \% \text { ), Glasgow score of } 3 \text { (mortality: } 62 \% \text { ) and oxygen saturation below } 80 \% \text { or stunning } \\
\text { (mortality } 76 \%) \text {. }\end{array}$} \\
\hline
\end{tabular}


Scanner data were recorded through the report of the radiologist. The CT scans that have shown a discrepancy with the clinic were reviewed by a senior radiologist to identify missed lesions during the first interpretation. Only the original traumatic lesions were identified.

The scanner was considered as positive when it is mentioned in the radiological report a traumatic appearance lesion at the considered level.

Data were processed with SPSS Version 20.0 and Excel 2013 software. The radio-clinical correlation was determined using the Kappa coefficient controlled by a confidence interval of 95\% [6]. The Kappa coefficient was interpreted according to Landis and Koch data [7], as indicated in Table 2.

\section{Results}

During the survey period, 180 patients that is $58.33 \%$ of men $(n=105)$ and $41.67 \%$ women $(n=75)$ were searched. The average age of patients was 32.71 years old with some extremes of 3 and 98 years old.

The highway accident predominated in $90 \%$ of injuries $(n=162)$. The high kinetic was the main reason that motivated the realization of a whole body scanner.

The medical transport was the most requested and performed in $34.4 \%$ of cases by firefighters, followed by the Emergency and Resuscitation Mobile Service in 28.9\% of cases.

Severe trauma status was observed in 155 patients that is $86.11 \%$ of the cases and had at least a Vittel criterion. This status was deemed subjective in 24 patients (13.33\%).

One hundred and twelve patients (62.2\%) had at least a clinical sign. The predominant clinical sign was pain, more frequent at the thoracic level in $28.9 \%$ of cases.

The computed tomography lesions searched by segments are reported in Table 3 and was dominated by rib fractures and pulmonary parenchymal contusions.

Table 2. Interpretation of kappa coefficient correlation.

\begin{tabular}{cc}
\hline ACCORD & KAPPA \\
\hline Very good & $>0.81$ \\
Good & $0.61-0.80$ \\
Average & $0.41-0.60$ \\
Poor (mediocre) & $0.21-0.40$ \\
Bad & $0.0-0.20$ \\
Execrable & $<0$ \\
\hline
\end{tabular}

Table 3. Division of scanographic lesions per segments scanned.

\begin{tabular}{ccc}
\hline Level & Scanographic lesions & $(\mathrm{n} \%)$ \\
\hline \multirow{2}{*}{ Cerebral } & Hematoma bruise & (ED 1.67\%; SD 1.11\%; IP 1.11\%) \\
& Oedeme hemorrhagic contusion & $1.11 \%$ \\
Spine & Craniofacial fracture & $1.11 \%$ \\
\hline \multirow{2}{*}{ Thorax } & Stable vertebral body fracture & $5 \%$ \\
& Unstable vertebral body fracture & $1.11 \%$ \\
\hline Abdomen & Rip fracture & $1.11 \%$ \\
\hline \multirow{2}{*}{ Pelvis } & Bruising parenchymal & $12 \%$ \\
& Splenic contusion & $6 \%$ \\
\hline
\end{tabular}

*ED: extra-dural, SD: subdural, IP: intra-parenchymal. 
These computed tomography scan tests were performed within 1 or 2 hours with some extra-times of 15 minutes and 24 hours after the patient arrival in the emergency unit.

After the completion of the whole body scan, $144(80 \%)$ injured patients were allowed to return home and 34 (18.9\%) of them had received hospital treatment in a specialized service. Two patients (1.1\%) were transferred to the Regional University Hospital Centre.

The average radiation dose received by patients was 3319.21 mGy.cm with some extremes of 2482 and 4920 $\mathrm{mGy} \cdot \mathrm{cm}$.

The radio-clinical correlation is shown in Table 4. In the fragmented analysis by level, the group corresponding to asymptomatic patients with a normal scanner was the most represented (56.7\% to 90.6\%). This proportion decreased to $34.4 \%$ when we grouped the different segments.

Patients with at least one clinical sign and a normal scanner were in majority, all level mixed (38.9\%). This percentage decreased slightly at each stage or level with variable percentages of $6.7 \%$ to $33.9 \%$.

The Table 5 describes the radio-clinical concordance/correlation according to the Kappa coefficient. The correlation between clinical sign and computed tomography lesions was poor all level mixed. It varied from "bad" and "average" according to the level. The best correlation was recorded at the pelvic level.

\section{Discussion}

The goals of this study were globally achieved even though it has some limitations mainly related to its monocentric nature and to a prior selection of patients transported in priority to the Regional University Hospital Centre.

Table 4. Clinical and scanographic correlation.

\begin{tabular}{|c|c|c|c|c|}
\hline Level & Clinical & Scanographic & Correlation & ${ }^{*}(\mathrm{n} / \%)$ \\
\hline & $-1-$ & $-1+$ & $+1-$ & $+/+$ \\
\hline \multirow{2}{*}{ Cerebral } & 148 & 1 & 23 & 8 \\
\hline & 82.2 & 0.6 & 12.8 & 4.4 \\
\hline \multirow{2}{*}{ Spine } & 102 & 3 & 61 & 14 \\
\hline & 56.7 & 1.7 & 33.9 & 7.8 \\
\hline \multirow{2}{*}{ Thorax } & 136 & 17 & 13 & 14 \\
\hline & 75.6 & 9.4 & 7.2 & 7.8 \\
\hline \multirow{2}{*}{ Abdomen } & 151 & 0 & 28 & 1 \\
\hline & 83.9 & 0 & 15.6 & 0.6 \\
\hline \multirow{2}{*}{ Pelvis } & 163 & 0 & 12 & 5 \\
\hline & 90.6 & 0 & 6.7 & 2.8 \\
\hline \multirow{2}{*}{ Total $^{* *}$} & 62 & 6 & 70 & 42 \\
\hline & 34.4 & 3.3 & 38.9 & 23.3 \\
\hline
\end{tabular}

* + +/+: Positive clinical and scan at the considered level; +/-: Positive clinical examination and negative scan at the considered level; -/+: Negative clinical examination and positive scan at the considered level; -/- Negative clinical examination and scan at the considered level. ${ }^{* *}$ All segments mixed.

Table 5. Interpretation of the radio-clinical correlation according to Kappa coefficient.

\begin{tabular}{cccc}
\hline Level & Kappa & Confidence interval (95\%) & Radio-clinical correlation \\
\hline Cerebral & 0.242 & $(0.19 ; 0.29)$ & Poor \\
Spine & 0.178 & $(0.12 ; 0.23)$ & Bad \\
Thorax & 0.384 & $(0.29 ; 0.48)$ & Bad \\
Abdomen & 0.057 & $(0 ; 0.11)$ & Average \\
Pelvis & 0.430 & $(0.30 ; 0.56)$ & Poor \\
Total & 0.350 & $(0.25 ; 0.45)$ & \\
\hline
\end{tabular}


We also note the biases inherent to retrospective studies, including inadequate intelligence data but mainly the mode of inclusion of severe trauma patients from the list of full body scanners made for emergencies in the base of the radiology department data. This method of inclusion sets aside the patients who underwent a full body scanner registered under another name in the computer base of Radiology.

The assessment of the benefit-risk balance of the whole body scanner protocol in terms of morbidity and mortality is limited by the lack of information on the fate of long-term patients.

However, this study has the merit of having allowed us to evaluate the relationship between clinical and scan globally through the kappa coefficient correlation, even if it is not the criterion choice to determine the interest of the systematic whole body scanner in our study's population.

The average age of our study's population was relatively young that is 32.71 years old (extremes 3 - 98 years old) with a male predominance (sex ratio: 1.4). At Marseille in France, CHAUMOITRE et al. got similar results, that is an average age of 34 year old in 2009 [8]. BABAUD et al. in 2012 had noticed an average age of 35.06 years old (extremes 15 - 88 years old) [3]. This finding could be related to the hyperactivity of men in general and youth in particular. The average age of patients in this study is lower than that reported in the literature; this could be explained by the inclusion of the pediatric population that has been excluded from the other studies above cited.

The highway accidents represent $90 \%$ of severe trauma causes in our study. These results are superimposed to those obtained in 2010 by TURK et al. as well as OBERLIN et al. in 2013 with respectively $64 \%$ and $60 \%$ of highway accidents [9] [10]. The highway accidents are dominated by car accidents that represented $70.6 \%$ in this study and following the same lines with the literature data namely 53\% for OBERLIN et al. in Grenoble and 80\% for SALIM et al. in Poitiers [10] [11]. The high kinetic was the most frequent Vittel criterion that is 76.6\% of the study population. This only reason demanded a whole body scanner, even in the absence of clinical signs.

Most severe trauma patients (81.6\%) are taking to emergency unit by a medical transport, in order of frequency, by the firefighters (34.4\%), the Emergency and Resuscitation Service (28.9\%) and by the private ambulances (18.3\%). The need for transportation by emergency medical units is directly related to the gravity/severity initially estimated by the accident mechanism and its potential lesion.

The issue of medical transport is to respect the concept of the "Golden Hour" to optimize the treatment in the first hour so as to stabilize the patient [12]. Despite this urgency, a significant number of patients in our series were transported to the emergency unit by an unsafe vehicle (6.1\%). This could be explained by the relative severity of the trauma of these patients.

The high kinetic was the most common severity criterion, its evaluation is often subjective because it is sometimes a personal assessment of a medical team member, or of emergency unit who witnessed the damage of the vehicle or an assessment of the place of the fall. The questioning sometimes difficult, doesn't always clarify the circumstances of the accident, mainly in absence of witnesses, in case of emotional shock or unconsciousness. In our study, $86.11 \%$ of patients had at least one Vittel criterion against $13.33 \%$ in which the assessment of severity criteria was subjective. Our results are significantly higher than those obtained by OBERLIN et al. in 2013 in Grenoble (France) who had found 51.5\% of objective criteria against $40.5 \%$ subjective criteria in his study [10].

One hundred and twelve patients (62.2\%) had at least one clinical sign. Our figures are lower than those obtained by OBERLIN et al. who found $85 \%$ of patients with symptoms over a population of 429 patients [10]. It is the same for TURCK et al. who recorded $75.6 \%$ of patients with symptoms over a population of 140 patients [9]. Thirty-one patients (17.2\%) had a positive clinical examination at the cerebral level, 75 at the spine (41.7\%), 27 at the thoracic (15\%), 29 at the abdominal level (16.1\%) and 17 at the pelvis level (9.4\%). These results are in the same line with those of OBERLIN et al. in the brain, spinal and pelvic level respectively $17.9 \%, 44.5 \%$ and 16.8 of clinical signs over 429 patients [10]. The tendency reversed at thoracic and abdominal level with respectively $44.5 \%$ and $37.8 \%$ of clinical signs. This difference in tendency would probably relate to the lack of clinical examination, sedation, analgesics and or to the alcoholization of these patients.

Only 48 patients (26.7\%) had a lesion in the computed tomography based on Vittel criteria. Our results are close to those obtained by BABAUD et al. in 2012, who found over 164 of whole body scan performed only $32.3 \%$ of abnormal computed tomography on the presence of Vittel criteria. According to BABAUD et al., the proportion of abnormal whole body scanner is significantly higher in the group of patients who received a targeted scan than those who received a justified whole body scanner only by the presence of Vittel criterion [3]. On the other hand, HELLER et al. in 2014 got, out of 481 whole body scanner oriented by anamnesis and clinic, 
only $1.5 \%$ of lesions with only minor traumas lesion [13]. Our figures are lower than those obtained by OBERLIN et al., who found in their multifaceted study 55.8\% of computed tomography lesions in a population of 429 patients based on TRENAU classification who correct the parameters of Vittel criteria [10]. It is the same for TURCK et al. who recorded 65\% of computed tomography lesions in 123 patients selected thanks to ISS score (Injury Severity Score) [9]. This static difference could be explained by the choice of scores or algorithm in the assessment of severity criteria in trauma patients during the pre-hospital sorting on the one hand and of the reputation of the Hospital centre study on the other hand. We notice that there is more abnormality in the scan using other criteria than those of Vittel as the ISS score. This score is limited to the most three serious injuries in three areas; it does not take into account the other less serious lesions or multiple lesions in the same areas. Vittel Criteria are responsible for an over sorting of serious trauma patients. They include patients with no serious element in the clinical examination. Out of 180 patients surveyed, only two had respiratory distress and $80 \%$ of them are directly discharged from the emergency department. This could also be explained by the proximity of the Regional University Hospital Centre (20 km, that is 20 min to our survey center) where patients in need of urgent and specific care are first taken to. The direct consequence of this practice is the low number of injuries recorded in our study and the return home of the majority of trauma patients (80\%) after performing the whole body scanner. Nevertheless $18.9 \%$ of patients were hospitalized in a specialized unit for monitoring or for special care. However, TILLOU et al. as well as TURK et al. had recorded respectively $27 \%$ and $10 \%$ of patients who were returned home after being checked-up in emergencies ward [9] [14].

In the fragmented analysis by level, the group corresponding to asymptomatic patients with a normal scanner is the most represented (56.7\% to $90.6 \%$ ), which is not in favor of the whole body scanner. Contrariwise, this proportion decreases to $34.4 \%$ when we group together the various segments. In other words, this means $34.4 \%$ of the whole body scanner could not have been realized. Patients with at least one clinical sign and a normal scanner were the most represented all level mixed together (38.9\%), but this proportion decreased slightly at each level with a varying percentage between $6 \%, 7 \%$ to $33.9 \%$. This therefore, results that the performance of a targeted scanner would be more beneficial for these patients. The correlation between the clinical signs and the computed tomography lesions was poor all level mixed. OBERLIN et al. have found a poor global correlation.

At cerebral level, the correlation was poor (0.242), with 8 computed tomography lesions out of 23 symptomatic patients for this level. One asymptomatic patient had an injury type of oedema-hemorrhagic contusion. This lesion is small in our study. This observation is comparable to that of TURCK et al. who found $100 \%$ of a VPN compared to CT that we compare to the gold standard diagnosis [9]. According to STIELL et al., minor cranial traumas do not require scanner if their conscience to the Glasgow Coma Score is 15, if they do not vomit more than once if they have no signs of skull fracture. Thus, it is probably necessary to perform a brain CT to stable trauma patients whose clinical examination is totally negative, namely, no initial loss of consciousness, a Glasgow Coma Score at 15, no pupil abnormality, no headache, no trace of cranial impact [15]. Figure 1 shows an extra dural hematoma that was symptomatic.

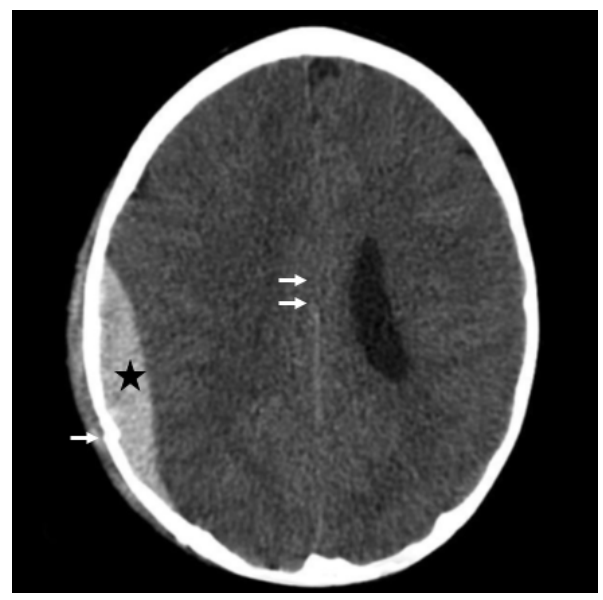

Figure 1. Cerebral scan without iodinated contrast injection: Axial-parenchymal window cut showing a spontaneous hyper density right temporal extra axial, bi-convex lens corresponding to an extra-dural hematoma right temporal (a star) in front of a fracture line (put a bone window and show) (b, arrow), and a mass effect on the right lateral ventricle (a, double arrows). 
The correlation is poor at the spine level (0.178) contrary to TURCK et al. or OBERLIN et al. results who had found mediocre correlation [9] [10]. Some stable vertebral fractures are found and required some immobilization. The conventional radiographies in our study could have at least detected some of these lesions but their long and difficult performance does not seem compatible with the taking care of our patients. We then believe that the scanner of the thoracolumbar spine could be systematic. Figure 2 illustrates asymptomatic unstable cervical spinal fracture.

At Thoracic level the correlation is also poor (0.384) with maximum asymptomatic lesions namely pulmonary contusion, rib fractures and pneumothorax. These results are comparable to those obtained by TURCK et al. or OBERLIN et al. [9] [10]. DEUNK et al. have demonstrated that there was no prognostic difference between severe trauma patients with occult pulmonary contusions and those who did not [16]. YADAV et al. as well have demonstrated in a meta-analysis in 2010, that there was no difference in mortality and the stay duration between the treated occult pneumothorax and those only monitored including mechanical ventilation [17]. Thus, the chest occult lesions could probably have gone unnoticed without a major prognostic.

At the abdomen, the clinical examination is unreliable, with a poor radio-clinical correlation. Even though we have recorded at the scanner only one lesion of splenic contusion, 8 our result is superimposed on the one of TURCK et al. or OBERLIN et al. [9] [10] (Figure 3). The management of these lesions has been changed by the introduction of an increased monitoring.

The best correlation was found at the pelvic level. This could be explained by the fact that pelvic fractures show violent traumas. The diagnosis of pelvic fracture in a conscious patient (whole body scanner $>13$ ) is easy and the negative clinical examination allows in these patients to limit unnecessary cliché made by the negative clinical examination because it is an expressive injuries due to the anatomy of the pelvic ring that has some weak areas [18].

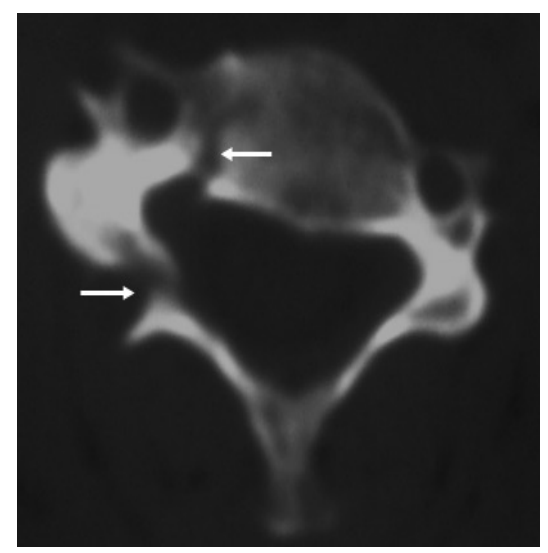

Figure 2. Cervical Scan without iodinated contrast injection: Axial bone window cut showing a right corporeo-laminar fracture of C3, unstable look (arrows).

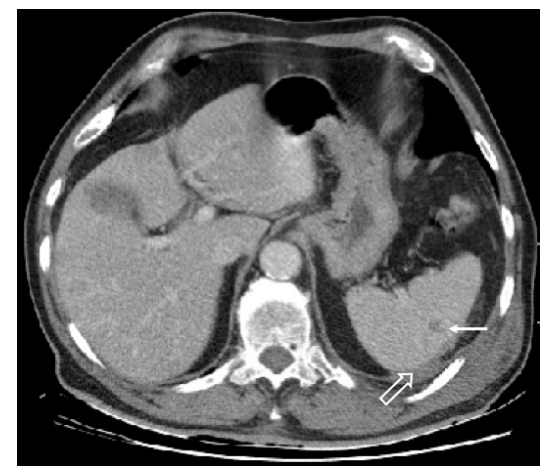

Figure 3. Abdominal scan with injection of iodinated contrast agent (portal phase): axial parenchymal window cut showing a small home of splenic contusion (full arrow), with discrete subcapsular hematoma (open arrow) from the vascular pedicle distance. 
The comparison of an oriented segmental strategy by clinical has a systematic whole body scanner strategy that has been made in several studies to severe trauma in general. TILLOU et al. found when systematically realizing the whole body scanner, $17 \%$ of unsuspected lesions by the traumatology team [14]. In the study of DEUNK et al., 242 patients out of 465 had at least one additional lesion discovered on the whole body scanner regarding a segmental strategy based on the clinical and standard cliché [16]. This finding is probably related to the lack of clinical examination, sedation, analgesics and or alcoholization of those patients that could influence the clinical examination. WEDEGARTNER et al. have shown that the oriented segmental scanner by clinical would permit an irradiation up to three times lower [19].

The average dose received by patient is $3319.21 \mathrm{mGy} . \mathrm{cm}$ with a maximum irradiation of $4920.06 \mathrm{mGy} \cdot \mathrm{cm}$ and a minimum of $2482.65 \mathrm{mGy} \cdot \mathrm{cm}$. BABAUD obtained some (dose-length product) values similar to that of our study that is a cumulative average (dose-length product) of $3283.31 \mathrm{mGy} \cdot \mathrm{cm}$. These values (figures) are up to the reference levels established by the Institute of Radiation Protection and Nuclear Safety (IRSN) [3]. In our study, $34.4 \%$ of asymptomatic patients have a negative scanner. This is a significant number of scanners that could have been avoided even if occult lesions were found (10\%), based on a good questioning and a thorough clinical examination of the patient, the occult lesions recorded were of minor severity. Those patients had unnecessary radiation and sometimes beyond the recommended doses.

\section{Conclusion}

The systematic performance of the whole body scanner based on Vittel criteria in severe trauma patients causes an over sorting and a poor clinical and computed tomography correlation. The results of this study call to reflect on the use of these Vittel criteria that could be refined to reduce the number of normal examinations carried out. The additional use of clinical data could make that improvement.

\section{References}

[1] Yeguiayan, J.-M. and Freysz, M. (2007) Support’s Severe Trauma in Non-Hospital Phase. In: Encyclopédie Médecine d'Urgence, Elsevier Masson, Paris, 25-200-B-10.

[2] Tentillier, E. and Masson, F. (2000) Epidemiology of Trauma. In: Beydon, L., Carli, P. and Riou, B., Eds., Severe trauma, Arnette, Paris, 1-15.

[3] Babaud, J., Ridereau-Zins, C., Bouhours, G., Lebigot, J., Le Gall, R., Bertrais, S., Roy, P.M. and Aubé, C. (2012) Benefit of the Vittel Criteria to Determine the Need for Whole Body Scanning in a Severe Trauma Patient. Diagnostic and Interventional Imaging, 93, 371-379. http://dx.doi.org/10.1016/j.diii.2012.02.007

[4] Lenfant, F., Yeguiayan, J.-M., Bensalem, D., Messant, I., Honnart, D. and Freysz, M. (2004) Initial Guidance to Emergency Trauma Severe. Refresher Courses SFAR. Elsevier SAS, Paris, 543-556.

[5] Riou, B., Vivien, B. and Langeron, O. (2006) What Priorities in the Initial Management of Polytrauma? Refresher Courses 2006. Elsevier Masson, Paris, 217-227.

[6] Cohen, J. (1960) A Coefficient of Agreement for Nominal Scales. Educational and Psychological Measurement, 20, 37-46. http://dx.doi.org/10.1177/001316446002000104

[7] Landis, J.R. and Koch, G.G. (1977) The Measurement of Observer Agreement for Categorical Data. Biometrics, 33, 159-174. http://dx.doi.org/10.2307/2529310

[8] Chaumoître, K., Cazalas, G., Bidault de l’Isle, L., Antonini, F., Léone, M. and Panuel, M. (2009) Supports Multiple Injuries by 64 Detectors Scanner: About 500 Patients. Journal de Radiologie, 90, 1178-1231.

[9] Turk, J., et al. (2010) Whole Body CT for Stable Severe Trauma: There Remains One Place to Clinical Examination: An Ob-Vationnelle Prospective Multicenter Study. Ph.D. Thesis, Joseph Fourier University, Grenoble, http://dumas.ccsd.cnrs.fr/dumas-00623738

[10] Oberlin, J., et al. (2013) The Whole Body Scanner Systematic Strategy: Is It Applicable to Severe Trauma Emergencies Stable? Ph.D. Thesis, Joseph Fourier University, Grenoble. http://dumas.ccsd.cnrs.fr/dumas-00875896

[11] Salim, A., Sangthong, B., Martin, M., Brown, C., Plurad, D. and Demetriades, D. (2006) Whole Body Imaging in Blunt Multisystem Trauma Patients without Obvious Signs of Injury: Results of a Prospective Study. Archives of Surgery, 141, 468-473. http://dx.doi.org/10.1001/archsurg.141.5.468

[12] Perrot, E., Aymard, J.-C. and Levraut, J. (2011) Transportation Management of a Serious Trauma. How Optimizer? Société Française de Médecine d’Urgence. Chapter 111.

http://docplayer.fr/2360462-E-perrot-1-j-c-aymard-2-j-levraut-3-1-prise-en-charge-initiale-d-un-polytraumatise.html 
[13] Heller, M.T., Kanal, E., Almusa, O., Schwarz, S., Papachristou, M., Shah, R. and Ventrelli, S. (2014) Utility of Additional CT Examinations Driven by Completion of a Standard Trauma Imaging Protocol in Patients Transferred for Minor Trauma. Emergency Radiology, 21, 341-347. http://dx.doi.org/10.1007/s10140-014-1200-x

[14] Tillou, A., Gupta, M. and Baraff, L.J. (2009) Is the Use of Pan-Computed Tomography for Blunt Trauma Justified? A Prospective Evaluation. Journal of Trauma, 67, 779-787. http://dx.doi.org/10.1097/TA.0b013e3181b5f2eb

[15] Stiell, I., Wells, G. and Vandemheen, K. (2001) The Canadian CT Head Rule for Patients with Minor Head Injury. Lancet, 357, 1391-1396. http://dx.doi.org/10.1016/S0140-6736(00)04561-X

[16] Deunk, J., Brink, M. and Dekker, H.M. (2009) Routine versus Selective Multidetector-Row Computed Tomography in Blunt Trauma Patients: Level of Agreement on the Influence of Additional Findings on Management. Journal of Trauma, 67, 1080-1086. http://dx.doi.org/10.1097/TA.0b013e318189371d

[17] Yadav, K., Jalili, M. and Zehtabchi, S. (2010) Management of Traumatic Occult Pneumothorax. Resucitation, 81, 1063-1068. http://dx.doi.org/10.1016/j.resuscitation.2010.04.030

[18] Muller, L., Lefrant, J.Y., Assez, N., et al. (2003) How to Manage Hypertension in Severe Trauma. In: The Severe Trauma, News in Prehospital Resuscitation 2002, Société française d'Éditions Médicales, 51-81.

[19] Wedegartner, U., Lorenzen, M. and Nagel, H.D. (2004) Radiologische Bildgebung beim Polytrauma: Dosisvergleich von Ganzkörper-MSCT und konventionellem Röntgen mit organspezifischer CT. Rofo, 176, 1039-1044. http://dx.doi.org/10.1055/s-2004-813216

\section{Submit or recommend next manuscript to SCIRP and we will provide best service for you:}

Accepting pre-submission inquiries through Email, Facebook, LinkedIn, Twitter, etc.

A wide selection of journals (inclusive of 9 subjects, more than 200 journals)

Providing 24-hour high-quality service

User-friendly online submission system

Fair and swift peer-review system

Efficient typesetting and proofreading procedure

Display of the result of downloads and visits, as well as the number of cited articles

Maximum dissemination of your research work

Submit your manuscript at: http://papersubmission.scirp.org/ 